\title{
DEVELOPMENT OF THE SPECIAL NEEDS CHILD'S VISUAL PERCEPTION (VISUAL PERCEPTION OF THE UPPER PERSPECTIVE)
}

\author{
Rania Essmat Muhammad Al-Sayed AL-QURBA *
}

Department of Printed Design, Faculty of Fine Arts, Alexandria University, Egypt

\begin{abstract}
Children with special energies are a category of society that needs special care, including educational aspects, which made them need a different and special kind of attention than their natural peers require, and since children with special energies are individuals with whom we have multiple common characteristics and they need to communicate with the surrounding environment. The most difficult types of disabilities are invisible disabilities that are not noticed by others, and it is not possible to determine from which category of children with special capacities can be classified. The functional disorder of the brain appears as a feature of children with special energies and it does not contain a single symptom, but it contains several symptoms, at least three of which must appear together in the same child, and from here it can be described as having a slight brain dysfunction. The functional disorder of the brain occurs as a result of deviations in the functions of the central nervous system, and these deviations appear in behaviour in the form of disturbances in attention, perception of concepts, language, memory, motor perception and impulsivity. This disorder affects the child's general intelligence level (less than average and above average), since the functional disorder of the brain affects the cognitive process of children with special energies, so it was necessary to find different ways and means to develop children's perception in various aspects, especially visual perception, which helps them interact with society.

Keywords

Development, Special Needs, Child's Visual Perception, Upper Perspective.
\end{abstract}

\section{Introduction}

Visual Perception is the interpretation of visual stimuli in terms of shape, size, and color, and giving these stimuli a significance and meaning, which helps to correct interpretations of the different visual effects of the surrounding environment.

We find that visual perception disorders have a great role in the emergence of learning difficulties due to the difficulty and interpretation of visual stimuli and give them their health significance due to the occurrence of confusion in the special needs child with other sensory stimuli when receiving visual stimuli.

\section{Research Problem}

Whereas a special child with mild and moderate disabilities does not enjoy seeing the top view from windows and balconies, especially depriving the natural child from that, and then he does not perceive the elements of nature around him from its upper perspective.

Hence the research problem appeared in answering the following questions:

- Do the illustrations of the upper perspective of different environments help the child to perceive the environment from around him?

- Do printed and interactive illustrations help to develop the child's upper perception?

*Corresponding author: finea-dean@alexu.edu.eg 


\section{Research Objectives}

> Access to a scientific method to solve the problems of visual perception of the upper perspective of the child with special needs through illustrations and prints.

\section{Research Significance}

Lack of scientific research and specialized centers for treating children with special needs, for drawings and multiple interactive means to develop the capabilities of visual perception of the upper perspective of the surrounding environments.

\section{Results}

- Illustrations of the upper perspective through different environments help the child to develop his visual perception.

- Using miniature models with natural materials (miniature wooden door) attract children's attention and develop their visual perception.

- Using miniature models printed through group play develops the child's perception of the upper perspective indirectly.

\section{Recommendations}

- Paying attention to the top perspective drawings for everything that the child's eye falls on in the surrounding environment to complement the drawings provided by the researcher and integrate them with the courses presented to the children.

- The necessity of using educational mini-models within schools and institutions to develop children's capabilities.

- The necessity of using printed educational miniature forms in group play.

\section{References}

1. Muhammad Ali Kamel: "Facing Academic Delays and Learning Difficulties", Ibn Sina Library for Publishing and Distribution, Arab Republic of Egypt, 2005.

2. Boutros Hafez Boutros: "Teaching Children with Learning Difficulties", Dar AlMasirah for Publishing, Distribution and Printing, 1st ed., 14330, 2009.

3. Salem Kamal: "Individual Differences between the Ordinary and the Extraordinary", Golden Pages Library, Riyadh, 1988.

4. Awatif Ibrahim: "Curriculum and Learning Methods in Kindergartens" The AngloEgyptian Library, Deposit No.

5. Cutlata, R., \& Tompkins, J_ "Fundamental of Special Education, What Every Teacher needs to know". Ohio, Merrill prentice Hall , 2003

6. Alan Macdonald RIBA- "WindfarmVisualization Perspective or Perception"

7. whittles publishing, Debnath, Scotland, Uk,2012, 
8. Gregory, R, -"Eye and Brain: The Psychology of Seeing" - Fifth Edition, oxford: Oxford University press, 1998.

9. Sarah Haley -"Perspective Drawing"-Tempe Digital,2018

10. STephanie-"The Urban Sketching Handbook Understanding Perspective"-Qublishing Group, USA lnc , 2016

11. Jorge paricio,M.1.D,ph.D.-"perspective Sketching: Freehand and Digital Drawing Techniques for Artists \& Designers Paperback "- Rockport publisher ,USA ,2015

12. Jorge paricio,M.1.D,ph.D-"perspective Sketching Freehand"-lbid,16,17,40

13. Ernest R Nerling -"Perspective Made Easy"-Dover publication, INC , Mineola, New York, 1999.

Received: February 11, 2018

Accepted: April 18, 2018 